\title{
A 23 Carat Alloy with a Colourful Sparkle
}

\author{
FC Levey, $M B$ Cortie \\ Mintek, Private Bag X3015, Randburg 2125, South Africa \\ and $L A$ Cornish \\ $\overline{\text { University of the Witwatersrand, Private Bag 3, WITS 2050, South Africa }}$
}

\begin{abstract}
Lightly etched surfaces of specimens comprised of the Au-Al $\beta^{\prime}$-phase exhibit a remarkable sparkling appearance and play of colour. An investigation of this phenomenon is described and explained here. The play of colour produced from individual grains as the sample is tilted in light is due to diffraction from arrays of very regular lamellae. However, consistently obtaining the desired microstructure requires an understanding of this alloy system's remarkable behaviour. Other technological properties which would be relevant to possible commercial application of this alloy are also discussed.
\end{abstract}

Heycock and Neville discovered at the start of this century that a phase, which they designated $\beta$, is formed between aluminium and gold at about 80 to 81 at $\%$ (or about $97 \mathrm{wt} \%$ ) Au $(1,2)$. At room temperature, the grains of this $\beta$-phase were found to consist of a multitude of lamellae. However, rapid quenching was necessary to ensure the retention of this phase at room temperature, indicating that the $\beta$-phase was thermodynamically stable only at elevated temperatures (1). The lamellae were evidently induced in the $\beta$-phase by the quenching step, and the possibility that they were the result of a partial decomposition of the $\beta$-phase into $\mathrm{Au}_{4} \mathrm{Al}$ and the $\mathrm{Au}^{-}$ rich $\alpha$-phase was originally mooted (1). Curiously, this structure could be preserved only in alloy samples that had been freshly solidified, and subsequent attempts to re-form the $\beta$-phase in alloys that had been thermally cycled produced another, quite different phase (1), which we now know to be $\mathrm{Au}_{4} \mathrm{Al}$. The behaviour of the metastable $\beta$-phase was investigated further by the present authors in a quest to find a high-caratage jewellery alloy that would exhibit a surface texture in a similar manner to the 18 carat 'Spangold' alloys (3-6).

\section{$\beta$-PHASE ELECTRON COMPOUNDS}

The $\beta$-phase in the Au-Al binary system has the same body-centred cubic crystal structure as the ' $\beta$-electron compounds' known from diverse alloy systems. These intermetallic compounds form frequently between elements of slightly differing electronegativity. Some better known examples are $\mathrm{CuZn}_{2} \mathrm{Cu}_{5} \mathrm{Sn}$ and $\mathrm{Cu}_{3} \mathrm{Al}$. These particular phases are characterized by their having the $c l 2$ body-centred cubic crystal structure and a ratio of valence electrons to atoms (e/a) of approximately 1.5 . In the case of the $\mathrm{Au}-\mathrm{Al}$ system, the relevant $e / a$ criterion is satisfied for a composition with the stoichiometry $\mathrm{Au}_{3} \mathrm{Al}$, whereas the actual $\beta$-phase that forms has a stoichiometry closer to $\mathrm{Au}_{4,2} \mathrm{Al}$. The reason for this discrepancy is not known to the authors.

The $\beta$-electron compounds are ductile, but generally not thermodynamically stable at room temperature. Nevertheless, in many cases they may be retained, in a modified form, at room temperature by a rapid quench. This provides a ductile material in alloy compositions that might otherwise be exceedingly brittle. For example, slow-cooled bronze of the stoichiometry $5 \mathrm{Cu}: 1 \mathrm{Sn}$ ('bell metal') is brittle and very difficult to machine, whereas the compound $\beta-\mathrm{Cu}_{5} \mathrm{Sn}$, freshly quenched from within its field of stability, is ductile, tough, and machinable (7). In most cases however, it is not the high temperature form of the $\beta$-phase that is retained at room temperature, but some derivative of it with a modified crystal structure. These new, metastable phases are generally formed from the parent $\beta$-phase by displacive and/or ordering transformation mechanisms. The back and forth transformation between two of these $\beta$-derived structures is the basis of the shape memory effect in various copper-base alloys (8). 
In the case of the Au-Al $\beta$-phase, the fate of the high temperature $c l 2$ phase on cooling depends on the rate of temperature change. If the phase is cooled exceedingly rapidly, for example by quenching a thin section into iced brine, then the $\beta$-phase transforms to a $\beta^{\prime}$-phase with a body-centred tetragonal crystal structure of the $t / 2$ type. This transformation is accompanied by considerable deformation of the crystal lattice, and each prior grain of $\beta$-phase becomes filled with very regular arrays of laths or twins. Interestingly, although the equilibrium phase diagram shows that the $\beta$-phase is stable only down to a little over $500^{\circ} \mathrm{C}$, it will actually survive for some time in newly solidified material down to about $425^{\circ} \mathrm{C}$ (1). However, unless this material is subsequently cooled very rapidly, such metastable $\beta$ will eventually decompose to a eutectoid mixture of the intermetallic compound $\mathrm{Au}_{4} \mathrm{Al}$ and $\mathrm{Au}$ when cooled further. The latter reaction is rapid, once initiated, and relatively exothermic, and is able to raise the temperature of the sample as high as $525^{\circ} \mathrm{C}$ (1). It is reported that once the compound $\mathrm{Au}_{4} \mathrm{Al}$ has formed in the sample, subsequent retention of the $\beta$-phase below about $500^{\circ} \mathrm{C}$ is not possible (1).

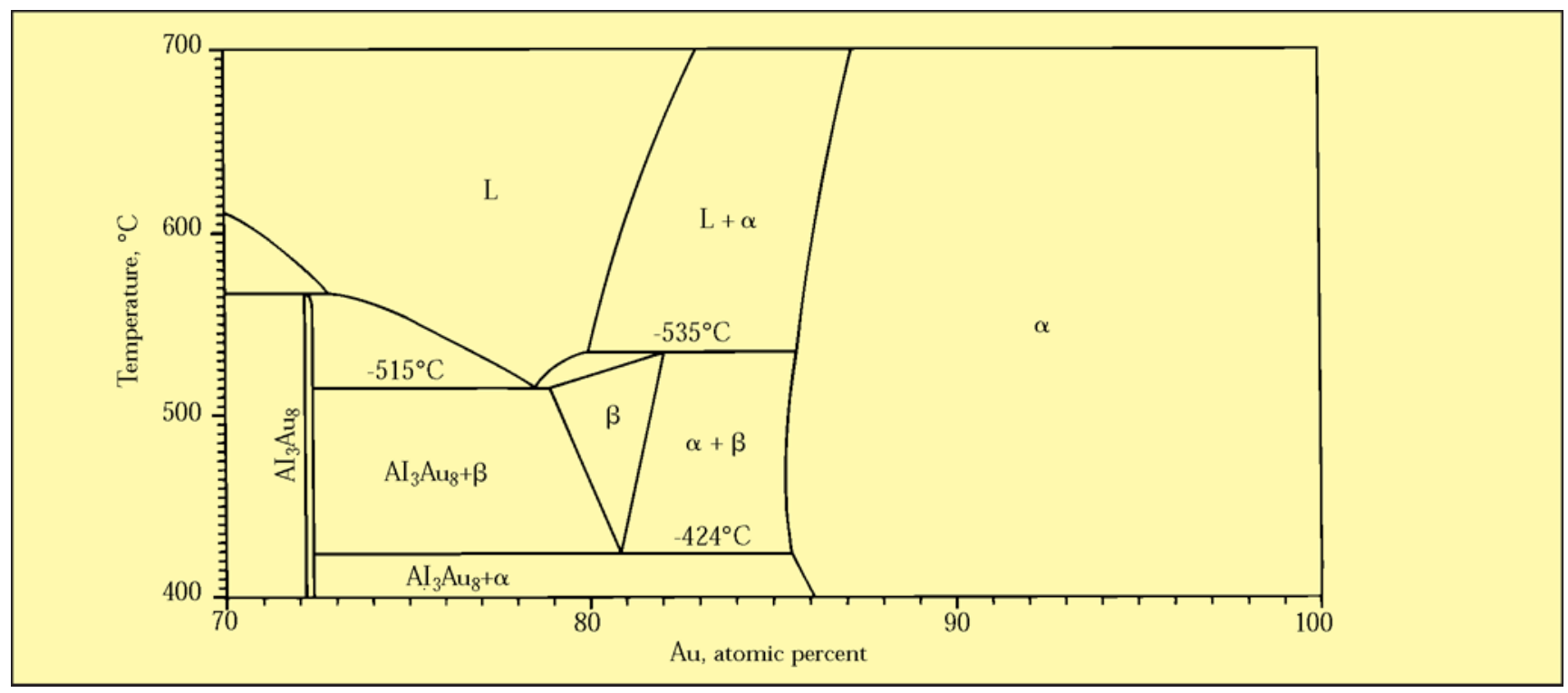

Figure 1 Metastable phase diagram for $A u-A l$ alloys cooling for the first time from the molten condition

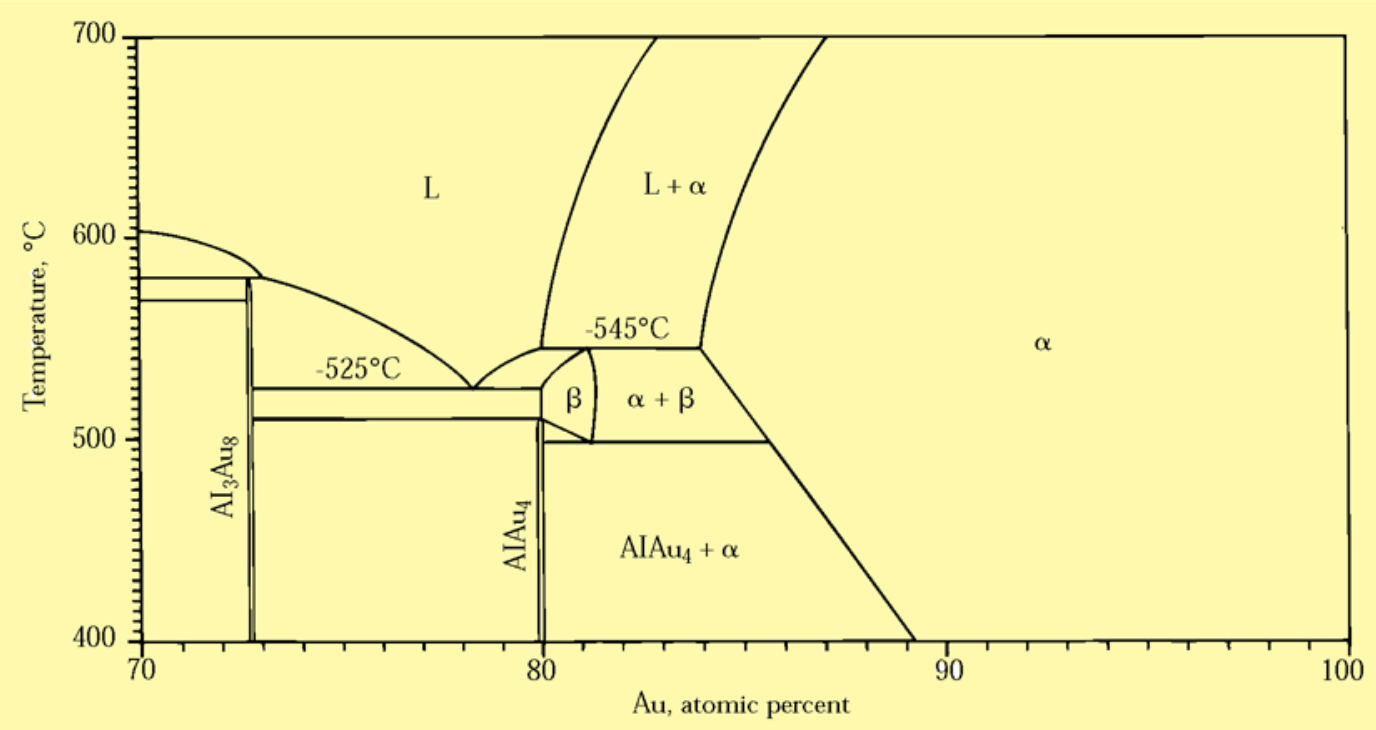

Figure 2 Currently accepted equilibrium diagram for Au-Al between 70 and 100 at $\% \mathrm{Au}$ 
Clearly, the initial formation of the $\mathrm{Au}_{4} \mathrm{Al}$ compound, which has a complex crystal structure of the $c P 20$ type, is impeded by nucleation difficulties. Once suitable nuclei are formed, and provided they are retained in the structure, further formation of this compound is rapid. This explains the initial puzzlement of Heycock and Neville, who noted that there were two rather distinct 'equilibrium' diagrams for this material, one for samples that had been freshly solidified and not yet allowed to cool below $400^{\circ} \mathrm{C}$ (Figure 1), and the genuine equilibrium diagram (Figure 2) for samples that had been allowed to form $\mathrm{Au}_{4} \mathrm{Al}$ at least once. These interesting phenomena proved to be by no means of only academic importance when the present authors set out to reproducibly manufacture visually attractive samples of the metastable low temperature phase!

\section{INVESTIGATION OF THE SHIMMERING EFFECT}

The first alloy to be investigated was prepared by arcmelting 3.0wt\% Al - 97.0wt\% Au (corresponding to 81.6at\% $\mathrm{Au}$ in Figures 1 and 2), with a resultant composition of $2.99 \mathrm{wt} \% \mathrm{Al}$. The sample was then subjected to a 20 hour anneal at $480^{\circ} \mathrm{C}$ followed by air cooling and, later, a further 10 minutes at $480^{\circ} \mathrm{C}$ followed by an iced brine quench. These heat treatments were part of a preliminary effort to find a successful heat treatment formula. However, in each of these instances the resulting microstructure was found to consist substantially of the hard, brittle, and relatively colourless $\mathrm{Au}_{4} \mathrm{Al}$ intermetallic phase. The alloy was then homogenized in the $\beta$-phase field at $520^{\circ} \mathrm{C}$ and quenched in iced brine to preserve the metastable phase structure. After polishing to a mirror finish and applying a light etch with an acidic chromium trioxide solution ${ }^{1}$, the resulting surface displayed a magnificent glittering aspect, with individual grains reflecting different colours of white, yellow, green, and blue respectively, with an effect not unlike pavée diamond inlays.

Subsequent samples were manufactured from a master alloy containing $2.92 \mathrm{wt} \% \mathrm{Al}$ (corresponding to 82.0at\% Au in Figures 1 and 2). This was produced by vacuum induction melting $96.9 \mathrm{wt} \% \mathrm{Au}$ and then adding $3.1 \mathrm{wt} \% \mathrm{Al}$. The as-cast alloy had a duplex microstructure consisting of a gold-rich $\alpha$-phase and a fine eutectoid mixture of the $\mathrm{Au}_{4} \mathrm{Al}$ intermetallic and $\alpha$-phases. After these samples had been given the

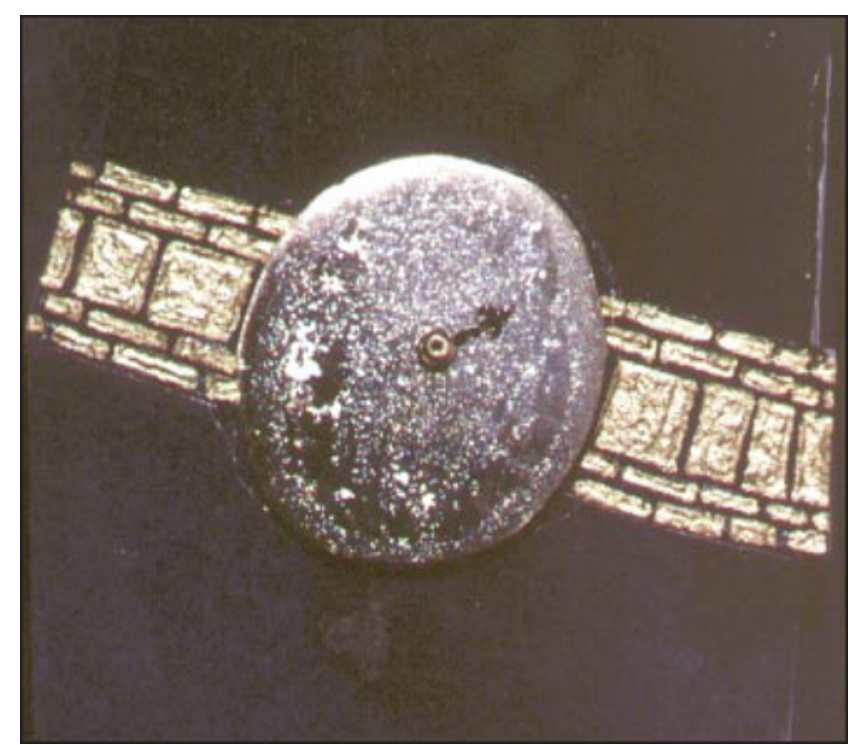

Figure 3 Polished and treated sample of the gold alloy, decorated to give an idea of its application as a material for the face of wrist watches. Note the multicoloured sparkles on the surface.

'betatizing' heat treatment, and were polished and etched in aqua regia', they also produced the shimmering surface effect displayed by the original alloy. Such material will be referred to here as ' $\beta$-quenched'. However, it was more difficult to obtain the shimmering effect in these alloys than it was in the original alloy, despite their similar compositions. This problem was evidently due to the slightly lower aluminium content, which caused these alloys to contain a significant amount of $\alpha$-gold, a feature which will be addressed later. This factor also caused an irregular grain size, as shown in Figure 3.

\section{Microstructure}

Microstructural examination of polished and etched sections revealed that the $\beta$-quenched samples consisted largely of polygonal grains of a light yellow phase that was evidently very extensively and regularly twinned. These specimens also possessed small regions of $\alpha$-gold, which in some cases could be seen to be the remnants of dendritic cores, and in others arose from smearing during polishing.

$\mathrm{X}$-ray diffraction analysis of these samples indicated that they consisted largely of the bodycentred tetragonal $\beta^{\prime}$-phase, with significant amounts of the $\alpha$-gold phase. The $\beta^{\prime}$-phase had lattice parameters of $a=3.100 \pm 0.003 \AA$ and $c=3.495 \pm 0.004 \AA$,

\footnotetext{
${ }^{1} 0.1 \mathrm{~g} \mathrm{CrO}_{3}$ in $10 \mathrm{ml} \mathrm{HNO}_{3}+100 \mathrm{ml} \mathrm{HCl}$

${ }^{2} 3$ parts $\mathrm{HCl}+1$ part $\mathrm{HNO}_{3}$
} 


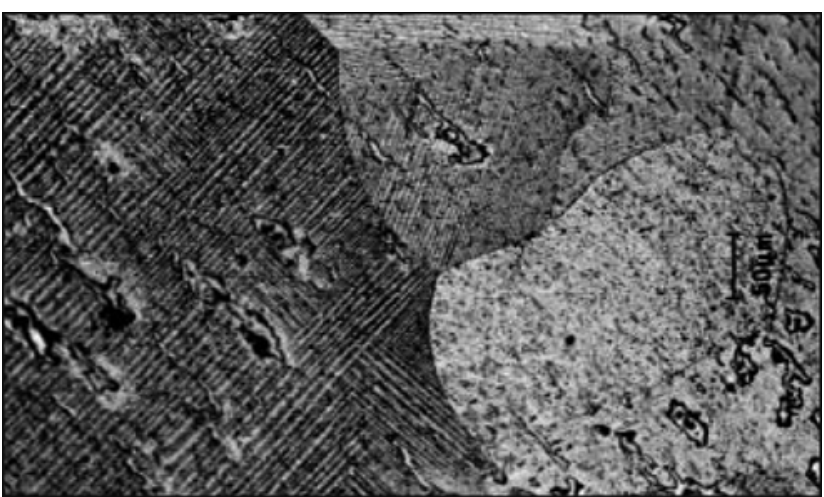

Figure 4 Lamellar microstructure of beta-quenched samples

whereas the standard lattice parameters listed for this phase are $a=3.108 \AA$ and $c=3.418 \AA$ (9). The small difference between the actual and published lattice parameters may be due to the slightly low aluminium content of these alloys. In any event, since the hightemperature parent $\beta$-phase is cubic, with lattice parameters of $a=3.24 \AA$ (9), it is evident that the phase transformation from $\beta$ to $\beta^{\prime}$ is accompanied by about a $4 \%$ contraction in the $a$ and $b$ directions of a given crystal and an expansion of about 5 or $6 \%$ in the $c$ direction. This magnitude of transformation strain could quite readily account for a highly twinned microstructure in the transformed phase.

Many of the $\beta$-quenched specimens also contained spherical regions of a rapidly dark-etching duplex structure (Figures 5 and 6) which were found to be caused by a slack quench. Specimens that had not been very speedily transferred from the furnace hot zone to iced brine readily developed differing proportions of this constituent, which manifested on the polished and etched surfaces as unsightly dark brown patches. Some specimens were allowed to totally transform to this condition and were then subjected to X-ray diffraction. These specimens did not contain any $\beta^{\prime}$-phase, and instead consisted substantially of the $\mathrm{Au}_{4} \mathrm{Al} \quad c P 20$ phase, with a lesser amount of $\alpha$-gold.

A sample that had been quenched from the twophase $\alpha$ plus liquid region would have been expected from consideration of the metastable phase diagram (Figure 1) to consist of $\alpha$-dendrites surrounded by a rim of $\beta^{\prime}$-phase set in an eutectic matrix of $\mathrm{Al}_{3} \mathrm{Au}_{8}+$ $\beta^{\prime}$. Alternatively, if the equilibrium phase diagram (Figure 2) had applied, this sample should have consisted of $\alpha$-dendrites surrounded by a rim of $\beta^{\prime}$-phase and a eutectic of $\mathrm{Al}_{3} \mathrm{Au}_{8}$ plus $\mathrm{Au}_{4} \mathrm{Al}$. In fact, $\mathrm{X}$-ray diffraction analysis showed the presence only of $\alpha$-gold, $\mathrm{Au}_{4} \mathrm{Al}$ and a trace of $\beta^{\prime}$-phase. Evidently a slightly modified version of Figure 1 is required to

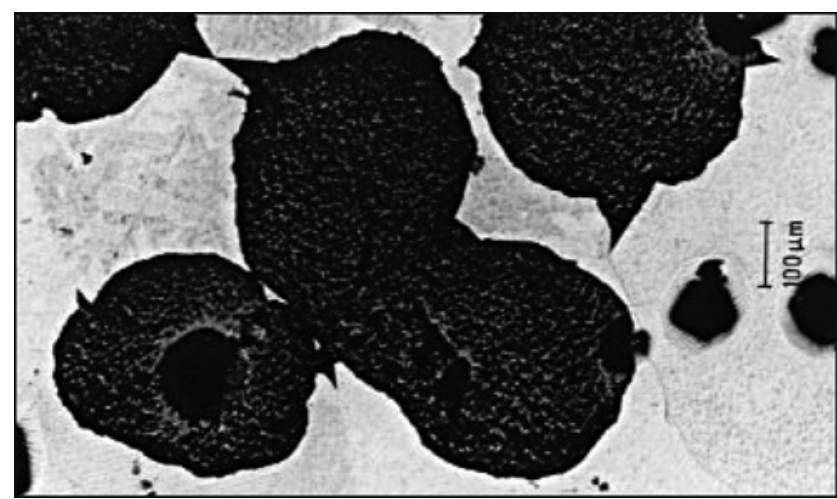

Figure 5 Spherical regions of the dark-etching constituent that has, in one case, nucleated on casting porosity

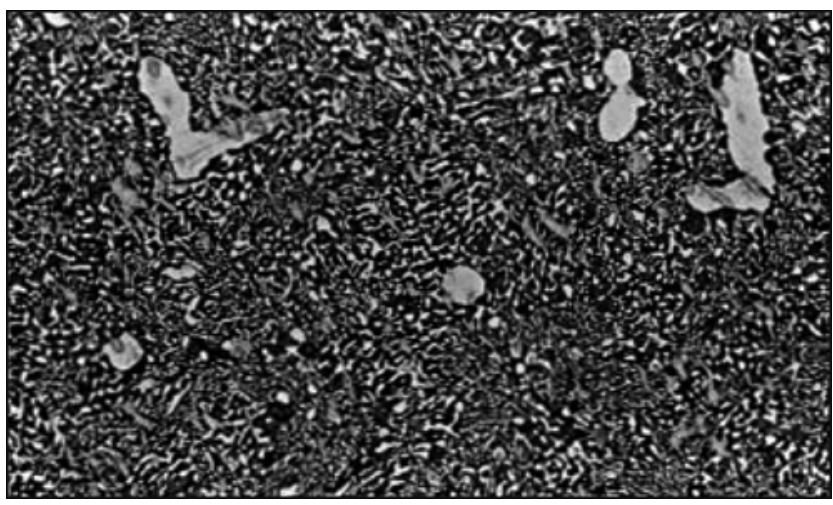

Figure 6 Higher magnification view of the dark-etching phase, showing that it consists of residual $\alpha$-gold dendritic cores, and a eutectoid mixture of the $\alpha$ - and $A u_{4} A I$ phases

account for the high rates of cooling applicable when partially-molten samples are water-quenched.

\section{Explanation of the Coloured 'Reflections'}

The spacing of the lamellae in the beta-quenched samples varied from grain to grain, ostensibly due to the differing planes of intersection of the sample surface with crystal orientation within the grains. The pieces which contained a larger number of grains with fine lamellar spacing were found to reflect more coloured light than pieces with a higher proportion of widely spaced laths. It appeared that this surface reflection of different wavelengths of the visible spectrum of light was due to a diffraction grating effect caused by the action of the etchant on the regularly spaced lamellae within each grain, as shown in Figure 7. (The same effect is visible on the surface of a CDROM.) As shown in Figure 8, reflections from a diffraction grating need to satisfy the following equation (10): 
$d \cdot \sin \theta=m \lambda$, for $m=0,1,2, \ldots$

where $d=$ distance between the rulings, $\lambda=$ wavelength of the incident light, and

$m=$ order of the spectrum produced.

Measured values of $d$ in these samples ranged from over $10 \mu \mathrm{m}$ to less than $0.5 \mu \mathrm{m}$. Table 1 lists the results of substituting these values and the wavelengths

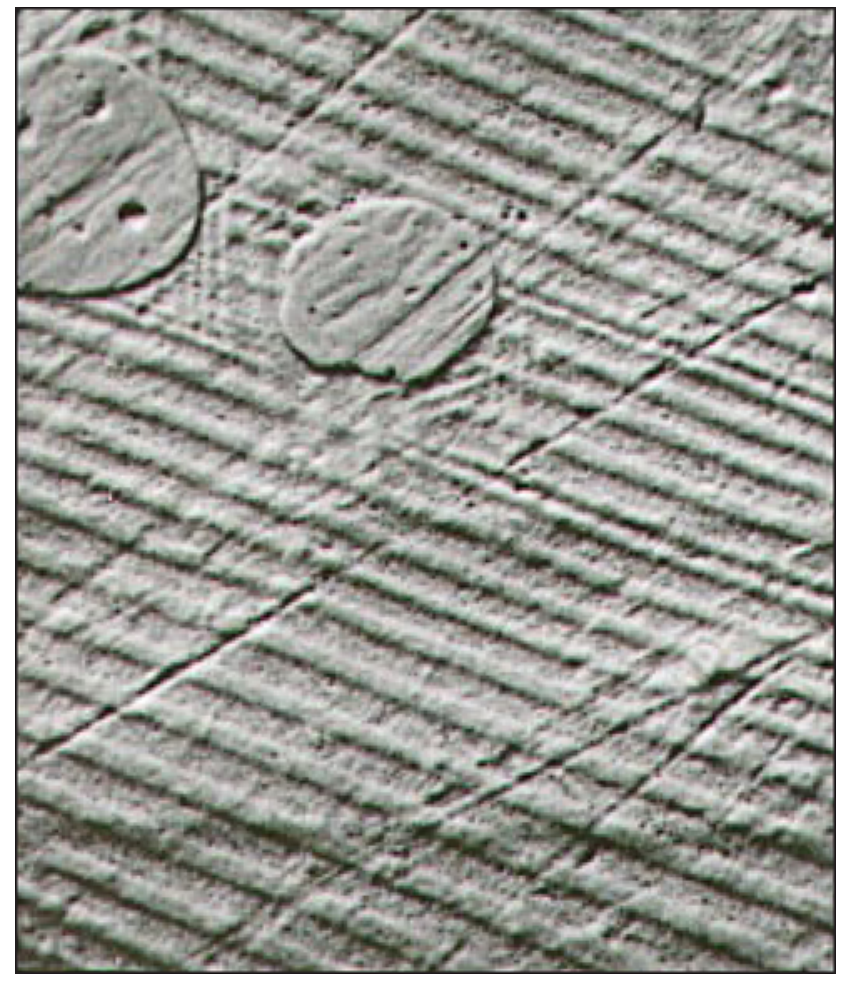

Figure 7 Diffraction grating produced by an array of parallel laths, viewed in a scanning electron microscope

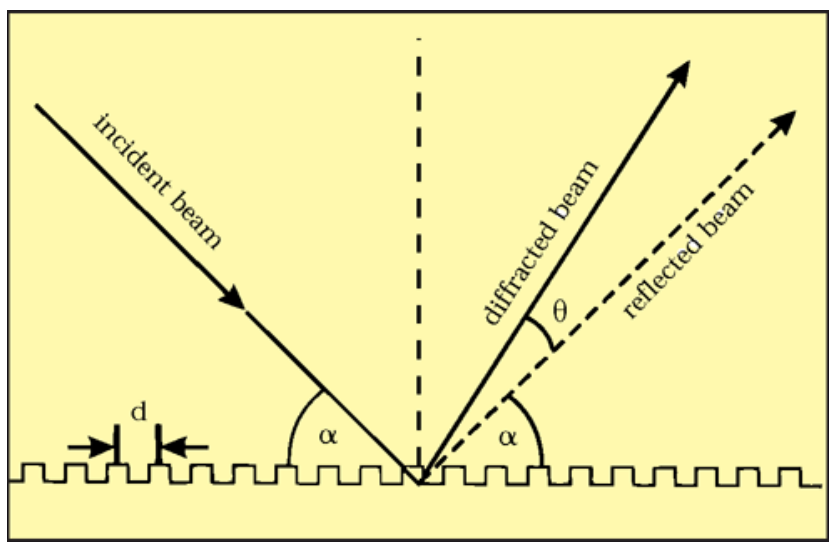

Figure 8 Diffraction of white light off a metallic reflection grating of violet and red light $(400 \mathrm{~nm}$ and $700 \mathrm{~nm}$ respectively) into the above equation. It is apparent that most of the observed colour must arise from first order diffraction maxima, since the higher order maxima overlap one another, and would not give clear individual colours. Two additional factors also apply. Firstly, it is a characteristic of these phenomena that the intensity of the diffracted light falls as the angle between it and the incident light beam increases. Secondly, the individual colours will be more easily resolved by the eye for a wider angular separation between the diffracted rays of red and violet light. Therefore, we believe that the most intense flashes of colour in these samples will be obtained for cases in which the spacing of the lamellae is around the 2 or 3 micrometer mark.

Table 1 Effect of lamellar spacing and wavelength of the incident light on the angle of diffraction (in degrees)

\begin{tabular}{lllllll}
$\begin{array}{l}\boldsymbol{d}, \\
\mu \mathbf{m}\end{array}$ & \multicolumn{2}{c}{$\begin{array}{c}\mathbf{1}^{\text {st }} \text { order } \\
\text { diffraction }\end{array}$} & \multicolumn{2}{c}{$\begin{array}{c}2^{\text {nd }} \text { order } \\
\text { diffraction }\end{array}$} & \multicolumn{2}{c}{$\begin{array}{c}3^{\text {rd }} \text { order } \\
\text { diffraction }\end{array}$} \\
0.5 & red & violet & red & violet & red & violet \\
2 & 53 & n.v. & n.v. & n.v. & n.v. & n.v. \\
5 & 11.5 & 20 & 24 & 44 & 37 & n.v. \\
10 & 4.6 & 8.0 & 9.2 & 16.2 & 13.9 & 24.7 \\
& 2.3 & 4.0 & 4.6 & 8.0 & 6.9 & 12.1
\end{tabular}

n.v. $=$ not visible

The calculated angles of reflection seem to be small, and one would expect that under normal circumstances the coloured light reflections would only be apparent if the surface was tilted to just the right angle. However, the etched surfaces of the individual grains of the alloy tilt relative to the surface at different orientations, in the manner so well known to metallographers. A wide variety of additional reflection angles therefore occur across the alloy surface, allowing a dynamic sparkling effect as the piece is moved and different grains catch the light. The effect is more spectacular when the incident light is generated by one or more point sources so that the number of colourful diffraction maxima from the grains is increased.

\section{Control of Prior $\beta$-Grain Size}

The visual appearance of the samples appears to depend closely on their grain size. Etched samples of the arc-melted alloy were consistently rated 'prettier' than those of the air-cast alloy. Subsequent 
investigation revealed that this was because the former had a consistent grain size of about 50 to $100 \mu \mathrm{m}$ whereas the air-cast alloys had an inhomogeneous distribution of grain sizes, with individual grains ranging from $3 \mu \mathrm{m}$ to $2 \mathrm{~mm}$.

The $\alpha$-phase regions in the induction-melted alloy appeared to pin the grain boundaries of the $\beta$-phase so that the grains only grew by "secondary recrystallization' (11) after extended annealing in the $\beta$-phase region. As a result of this phenomenon, the grain size distribution in a material becomes bimodal because most grains are too small to overcome the pinning restraint of the second phase regions located at their boundaries. Those few grains that fortuitously grow beyond some critical size however, become freed of the restraints imposed by the second phase regions, and then are free to grow very large indeed. As a result, the air-cast alloy pieces had grains that were either too small or too large for optimum light reflections, or were a mixture of very small and very large grains. Despite this, it was possible to produce some unusual and pretty pieces with mixed grain sizes using this phenomenon (as in Figure 3, for example). It was thus apparent that the arc-melted alloy contained the correct amount of aluminium to place it squarely in the $\beta$-phase field while the inductionmelted material lay on the gold-rich edge of the $\beta$ phase field.

\section{Effect of Heat Treatment}

It was found that air-cast samples with a thickness of 5 mm or more could not be quenched rapidly enough to stabilize the $\beta^{\prime}$-phase, whereas those with a thickness of $2 \mathrm{~mm}$ or less could be quenched very readily. It was also found that the air-cast pieces required more rapid quenching than the original alloy to prevent growth of the undesirable duplex structure. The gold-rich $\alpha$-phase present in the latter alloys evidently acted as nucleation sites for the growth of the undesirable duplex structure during quenching, since in many cases a bleb of $\alpha$-gold was visible in the centre of such $\mathrm{Au}_{4} \mathrm{Al}$ plus Au eutectoid masses.

The intensity of the 'shimmer' can be optimized with etching techniques, as well as heat treatment. It was found that, in addition to controlling the grain size, numerous 'betatizing' cycles tended to cause some of the grains to etch browner than usual, thus dulling the intensity of the shimmer. The length of time in the etching solution is also critical. The shimmer becomes more intense with a deeper etch, but over-etching causes pitting which dulls the surface.

\section{MANUFACTURING POSSIBILITIES}

The logical application for this alloy would be in jewellery. However, jewellery alloys need to meet certain requirements before they will be accepted by the industry. For example, the alloy should be castable, possess a fair amount of ductility and impact resistance, have an appealing colour, and resist oxidation and corrosion. Wear resistance is an attractive, but not essential, property. The extent to which the $\mathrm{Au}-3 \mathrm{wt} \% \mathrm{Al}$ alloy meets these requirements is discussed below.

\section{Castability}

The alloy casts well and, depending on composition, has a melting temperature between 550 and $600^{\circ} \mathrm{C}$. For air casting, the authors recommend a pouring temperature of $650^{\circ} \mathrm{C}$. The moulds used were also preheated to $650^{\circ} \mathrm{C}$. The alloy has excellent formfilling properties. A pinch of potassium pyrosulfate flux was added to prevent excessive oxidation of the aluminium. However, the alloy is brittle in the as-cast state due to the presence of the intermetallic $\mathrm{Au}_{4} \mathrm{Al}$ compound. It is expected that an investment-casting technique would give acceptable castings, provided that care was taken when 'divesting' the alloy. The alloy should be given a 'betatizing' heat treatment as soon thereafter as practicable, since it is much tougher in the $\beta$-quenched condition.

One drawback of the low melting point of this alloy is that it is too low to allow the use of any of the commercially available gold solders.

\section{Polishing}

This alloy polishes readily on metallurgical polishing cloths when it is in the $\beta$-quenched condition. Using this technique, the surface being polished is kept cool and moist. The duplex alloy does not polish as readily, with the abrasive medium (diamonds) becoming embedded in the gold-rich phase. Difficulty was experienced using the conventional buffing wheels and jeweller's rouge.

\section{Density}

The density of the $\beta$-quenched alloy is $16.8 \mathrm{~g} / \mathrm{cm}^{3}$. This value is between that of a standard 22 carat alloy $\left(17.8 \mathrm{~g} / \mathrm{cm}^{3}\right)$ and a standard 18 carat alloy $(15.6$ $\left.\mathrm{g} / \mathrm{cm}^{3}\right)$ (12). The lower density is due to the aluminium content and makes it possible for the jeweller to produce larger pieces with a given content of gold. Alternatively, conventionally sized pieces such as earrings should be more comfortable to wear 
compared to those made from conventional highcaratage alloys.

\section{Colour}

The as-cast alloy has a silvery colour which is evidently also the colour of the $\mathrm{Au}_{4} \mathrm{Al}$ phase. The colour of the $\beta$-quenched alloy in the unetched condition is very close to that of Gold 990. However, once etched, the alloy is predominantly yellow with flashes of white, red, and blue. The CIELab colour coordinates vary considerably due to the different colours on the surface (Figure 9). The colour difference between the $\mathrm{Au}_{4} \mathrm{Al}$ phase and the $\beta^{\prime}$-phase makes it easy to see whether a piece has fully transformed during the 'betatizing' heat treatment.

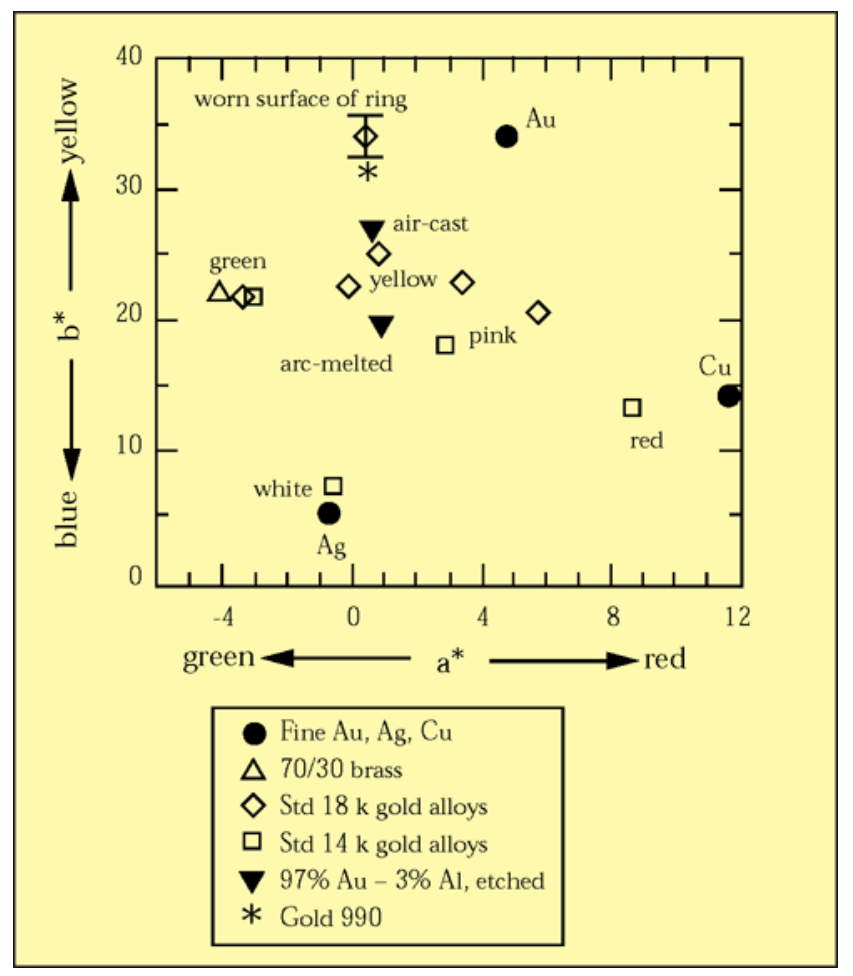

Figure 9 CIELab colour coordinates for the present alloy

The difference in colour between the $\beta^{\prime}$ - and Aut $1_{4} \mathrm{Al}$-phases can be attributed to the different electronic structures of the phases and, as in other metals, is related to the energy states of the free conduction electrons (13). The free electrons in metallic substances can absorb incident energy and undergo a band transition, either from the conduction band to a band with a higher energy, or from a band with a lower energy to the conduction band. If these quanta of energy match those of the incoming visible light, then those specific wavelengths of light will be absorbed. The light reflected from the metallic substance will then no longer be white.

As an example of the first instance (13), the spectacular colour of the intermetallic compound $\mathrm{AuAl}_{2}$ can be ascribed to free electrons undergoing band transitions from the Fermi level to unoccupied states of higher energy bands at energies corresponding to wavelengths in the visible spectrum between those of red and violet. The red and violet wavelengths are reflected from the surface, producing the characteristic colour associated with this compound. In the case of the second instance (13), free electrons in gold undergo a band transition from a d-band to unoccupied states in a conduction band above the Fermi level, with corresponding and increasing absorption of photons from around $2.3 \mathrm{eV}$ upwards. Incident light with an energy of $2.3 \mathrm{eV}$ corresponds to a wavelength of about $540 \mathrm{~nm}$ (the yellow-green part of the visible spectrum), so the red to yellow sections of the visible spectrum predominate in the light reflected from the metallic surface. On the other hand, the energy gap between the d-bands and the Fermi level of silver is so large that an incident energy higher than that of violet light is required for the band transition. The whole visible spectrum is thus reflected from the surface, giving the metal its characteristic white appearance.

\section{Wear Resistance}

Wear resistance is often related to hardness. The $\beta^{\prime}$-phase of the arc-melted alloy had a hardness of around $220 \pm 6 \mathrm{Hv}_{30}$. This is extremely hard for a 23 carat gold alloy. By comparison, pure gold has a Vickers hardness of around 20 (14) and the hardness of a standard 22 carat gold alloy ranges from 70 to 165 $\mathrm{Hv}_{1}$, depending on annealing treatments and the amount of cold work it has experienced (12). The hardness of samples substantially comprising the $\mathrm{Au}_{4} \mathrm{Al}$ phase could not be accurately determined due to the brittle nature of that phase, but was estimated to be at least $100 \mathrm{Vickers}$ points higher than that of the $\beta^{\prime}$-phase.

The durability, toughness, and wear resistance of this alloy were confirmed by making a ring of the aircast alloy in the $\beta$-quenched condition. This ring was worn continuously by one of the authors for over two years. The wear rate was similar to that of a conventional 18 carat gold alloy. However, the shimmering effect wore off quickly, so the use of this alloy should be restricted to articles which are subjected to minimal abrasion. 


\section{Impact Resistance and Ductility}

The alloy in the as-cast form is extremely brittle. However, the toughness is improved by the 'betatizing' heat treatment. An alloy in the $\beta$-quenched condition can withstand a number of impacts and can withstand light cold reductions (probably not more than 10\%).

It is also possible to hot work pieces of the alloy into fairly thin sheets at around $520^{\circ} \mathrm{C}$. However, if any secondary recrystallization or overheating occurs, then an inhomogeneous grain size is produced. Conventional heat treatment techniques were unsuccessful in restoring the original structure of such material with its characteristic brilliance in the etched state. This difficulty appeared to be largely due to grain pinning by particles of the $\alpha$-phase in the inductionmelted alloy.

This alloy is not recommended for applications with repeated impacts, such as rings, although the ring referred to in the previous section was still mechanically sound after more than two years of continuous use. It must be emphasized that the duplex structure of $\mathrm{Au}_{4} \mathrm{Al}+\mathrm{Au}$ which can form is extremely brittle and the proportion of this eutectoid mixture should be kept to the absolute minimum in finished pieces.

\section{Corrosion and Oxidation Resistance}

Rough and polished surfaces of both the $\beta^{\prime}$-phase and the undesirable duplex structure were unaffected by immersion in artificial sweat ${ }^{3}$ for two months. No cracking, pitting, oxidation, or mass loss was evident.

The surface of the alloy in both the etched and unetched conditions oxidizes slightly in air so that the yellow colour deepens.

\section{PROGNOSIS}

The authors accept that the unusual nature of this alloy will inhibit its widespread adoption by industry. Nevertheless, its use offers a skilled and adventurous manufacturer the opportunity to bring novel, interesting and attractive 23 carat items to the market. The magnificent sparkles and play of colour on wellprepared surfaces strongly suggest that the alloy could be used to produce truly magnificent evening jewellery. Our final figure (Figure 10) merely hints at some of the possibilities.

$\overline{33.75 \mathrm{~g} \mathrm{NaCl}+0.6 \mathrm{~g} \mathrm{KCl}+1.35 \mathrm{ml} \text { lactic acid }+0.5 \mathrm{~g} \text { urea made up to }}$ $500 \mathrm{ml}$ with de-ionized water

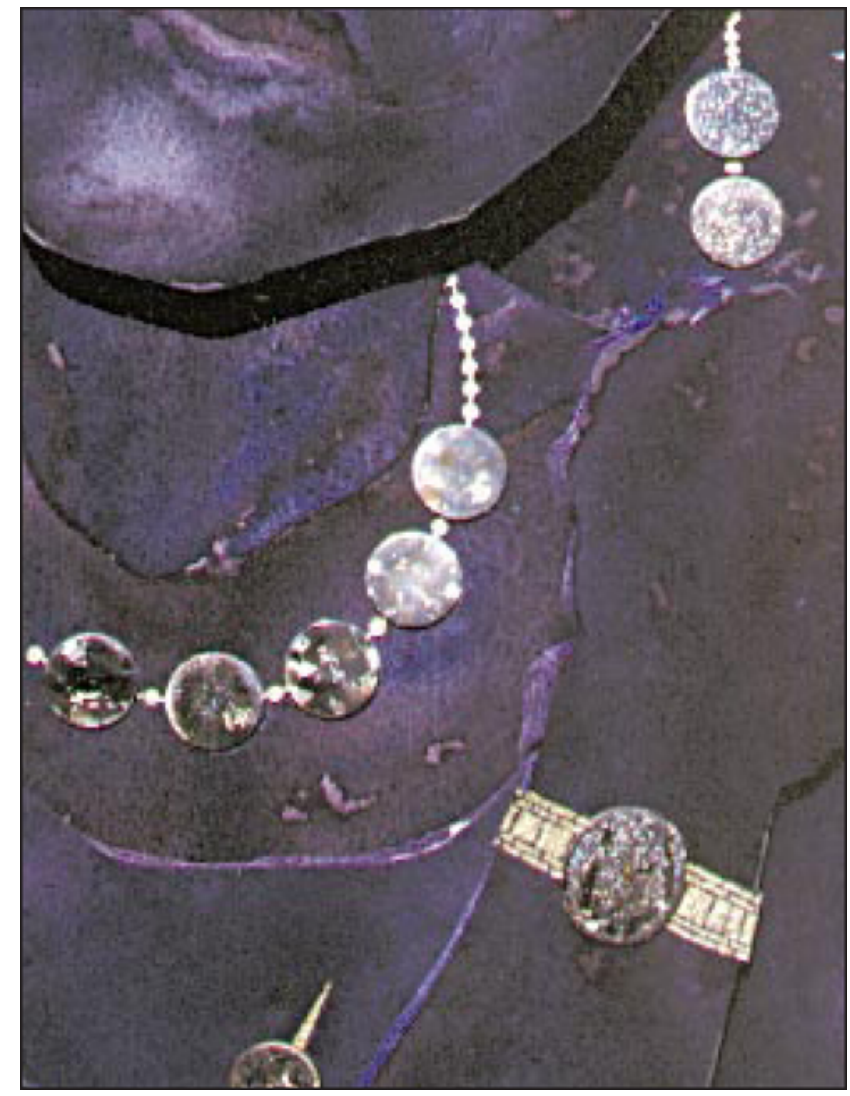

Figure 10 Some ideas for using this 23 carat alloy to its best advantage

\section{ACKNOWLEDGEMENTS}

This paper is published by permission of Mintek. The work was jointly sponsored by Mintek and the World Gold Council

\section{ABOUT THE AUTHORS}

Mrs Fiona Levey and Dr Mike Cortie are professional engineers in the Physical Metallugy Division of Mintek, South Africa. They have collaborated on a variety of projects, including studies of ferroalloy granulation and the $\mathrm{Au}-\mathrm{Al}-\mathrm{Cu}$ system. $\mathrm{Dr}$ Lesley Cornish is a Senior Lecturer at the School of Process and Materials Engineering, at the University of Witwatersrand, Johannesburg, and specializes in phase diagram studies.

REFERENCES - see page 102 